\title{
INTESTINAL AND EXTRAINTESTINAL NEOPLASIA IN PATIENTS WITH INFLAMMATORY BOWEL DISEASE IN A TERTIARY CARE HOSPITAL
}

\author{
Fábio Guilherme CAMPOS, Magaly Gemio TEIXEIRA, Arceu SCANAVINI, \\ Maristela Gomes de ALMEIDA, Sergio Carlos NAHAS and Ivan CECCONELLO
}

\begin{abstract}
Context - The development of neoplasia is an important concern associated with inflammatory bowel disease (IBD), especially colorectal cancer (CRC). Objectives - Our aim was to determine the incidence of intestinal and extraintestinal neoplasias among patients with inflammatory bowel disease. Methods - There were retrieved information from 1607 patients regarding demographics, disease duration and extent, temporal relationship between IBD diagnosis and neoplasia, clinical outcomes and risk factors for neoplasia. Results - Crohn's disease (CD) was more frequent among women $(P=0.0018)$. The incidence of neoplasia was higher in ulcerative colitis (UC) when compared to CD $(P=0.0003)$. Eight $(0.99 \%)$ patients developed neoplasia among 804 with CD: 4 colorectal cancer, 2 lymphomas, 1 appendix carcinoid and 1 breast cancer. Thirty (3.7\%) patients developed neoplasia among the 803 UC: 13 CRC, 2 lymphomas and 15 extraintestinal tumors. While CRC incidence was not different among UC and CD (1.7\% vs $0.5 \% ; P=0.2953)$, the incidence of extraintestinal neoplasias was higher among UC $(2.1 \% \mathrm{vs} 0.5 \%, P=0.0009)$. Ten $(26.3 \%)$ patients out of 38 with neoplasia died. Conclusions - CRC incidence was low and similar in both diseases. There was a higher incidence of extraintestinal neoplasia in UC when compared to CD. Neoplasias in IBD developed at a younger age than expected for the general population. Mortality associated with malignancy is significant, affecting 1/4 of the patients with neoplasia.
\end{abstract}

HEADINGS - Intestinal neoplasms. Colorectal neoplasms. Inflammatory bowel diseases. Colitis, ulcerative. Crohn's disease.

\section{INTRODUCTION}

The association between inflammatory bowel diseases (IBD) and colorectal cancer (CRC) was described many decades ago ${ }^{(8,29,41)}$, and today there is substantial evidence that this group of patients are at increased risk for developing colorectal and other malignancies in the setting of chronic inflammation and displasia. While this risk has been historically accepted for ulcerative colitis (UC), it is still controversial for Crohn's disease (CD). Estimates for CD range from lower than expected risk to an increase of up to 7 times the normal risk in the case of $\mathrm{CRC}^{(16,32)}$. A recent meta-analysis demonstrated an increased risk of small bowel, colon, extraintestinal cancers and lymphoma in patients with $\mathrm{CD}^{(40)}$.

The actual incidence of malignization, the interval of time necessary to develop a cancer and the factors that may contribute for its manifestation are unknown. While an overestimated incidence may derive from tertiary centers where the disease is usually severe and more extensive, a less dramatic figure is extracted from population-based studies. Moreover, it is possible that biologic therapy and immunosupressants that are currently used nowadays may affect this incidence ${ }^{(24)}$.

When compared to sporadic CRC, IBD-associated tumors usually occur in earlier in lifetime and develop as flat lesions in regions exhibiting dysplasia. Mucinous and synchronous lesions are also important characteristics of this population ${ }^{(23)}$. Factors associated with an increased risk of CRC are colitis duration and extension, early onset, family history of CRC, primary sclerosing cholangitis and histological features such as dysplasia or severity of inflammation. Otherwise, surgical treatment, surveillance and chemoprevention may help reduce this risk ${ }^{(4)}$.

The present study was designed to evaluate and compare the risk of intestinal and extra intestinal cancer in patients with UC and Crohn's disease. Thereafter, the characterization of this risk may help us identify features that are probably enrolled in prevention and selection of patients at greater risk. 


\section{METHODS}

This study has been approved by the scientific-ethics committee of our hospital and have therefore been performed in accordance with the 1964 Declaration of Helsinki. Patient data was prospectively collected since the first medical visit, being constantly actualizated during follow-up.

Between September 1984 and September 2007, 1607 patients were diagnosed with IBD (804 CD and $803 \mathrm{UC}$ ). Data regarding diagnosis, treatment and clinical outcomes were prospectively registered in a protocol containing all information since the first appointment. IBD diagnosis was made based on clinical, radiological, endoscopic and histological exams. Extent of CD was defined as colitis, enteritis, enterocolitis and perineal exclusively. Extent of UC was defined as extensive, left-sided and proctitis.

Information collected from medical records included demographics, IBD duration, extent of disease, temporal relationship between diagnosis of inflammatory bowel disease (IBD) and intestinal/extraintestinal neoplasia, clinical outcomes and potential risk factors for neoplasia (drugs, family history of cancer, smoking and association with sclerosing cholangitis).

Follow-up data was obtained through regular outpatient visits, that were scheduled every 6 months or more frequently if they needed orientation regarding medications, symptoms control, clinical or radiological evaluation. During follow-up, patients were routinely evaluated through biochemical tests and colonoscopy according to the symptoms (and every year after 10 years of diagnosis. Radiological investigation (ultrasonography, computer tomography and magnetic resonance) was indicated as necessary.

Neoplasia incidence was determined for patients with UC and $\mathrm{CD}$. The comparison of IBD patients with and without neoplasia was established through chi-square and Fisher's exact tests. The test of proportion was used to compare gender prevalence among the groups. All the analysis was performed using Statistical Package for the Social Sciences (SPSS) 13.0 (Chicago, IL). The threshold for statistical significance was predefined as $P<0.05$.

\section{RESULTS}

Most (76.2\%) of the 1607 IBD patients were Caucasians. As seen in Tables 1 and 2, gender distribution in this study revealed a prevalence of women $(P=0.001)$ among $C D$ $(55.2 \%$ vs $44.8 \%)$ and UC patients $(59.5 \%$ vs $40.5 \%)$, but the CRC incidence was similar in both sexes $(P=0.4)$.

Thirty-eight $(2.4 \%)$ patients developed some type of

TABLE 1. Descriptive data on genders for patients with CD and CD associated to neoplasia (colorectal cancer, lymphoma and other tumors)

\begin{tabular}{lccccc}
\hline Sex & $\begin{array}{c}\text { CD } \\
(\mathbf{n}=804)\end{array}$ & $\begin{array}{c}\text { CD+NEO } \\
(\mathbf{n}=8)\end{array}$ & CD+CRC & CD+LY & CD+OT \\
\hline Female & $439(55.2 \%)$ & $4(50 \%)$ & $2(25 \%)$ & 0 & $2(25 \%)$ \\
Male & $357(44.8 \%)$ & $4(50 \%)$ & $2(25 \%)$ & $2(25 \%)$ & 0 \\
\hline
\end{tabular}

$\mathrm{CD}=$ Crohn's disease $; \mathrm{NEO}=$ neoplasia $; \mathrm{CRC}=$ colorectal cancer $; \mathrm{LY}=$ lymphoma; $\mathrm{OT}=$ other tumors neoplasia during follow-up. Within this group, only two were receiving immunosuppressants and none of them had received anti-TNF therapy. Both patients receiving azathioprine were diagnosed with an eye tumor and a right colon cancer. There was no diagnosis of anal or small intestine carcinoma in any IBD patient.

Two (11.7\%) out of 17 patients that developed CRC had multiple lesions along the colon.

Table 3 shows that although the incidence of neoplasia was significantly higher in $\mathrm{UC}(\mathrm{n}=30 ; 3.7 \%)$ when compared to $\mathrm{CD}$ patients ( $\mathrm{n}=8 ; 0.9 \%$ ) (Qui-square $P=0.0003$ ), there was no statistical difference regarding the incidence of CRC ( $1.7 \%$ in $\mathrm{UC}$ vs $0.5 \%$ in CD, Fisher $P=0.2$ ). Otherwise, the incidence of extraintestinal neoplasia was higher among UC patients $(2.1 \%$ vs $0.5 \%)$ (Chi-square $P=0.0009)$.

\section{Patients with CD}

Eight $(0.99 \%)$ patients developed some kind of neoplasia among 804 DC patients (Table 1). Among five patients with $\mathrm{CD}$ colitis, there were found three CRC (one of them diagnosed with five synchronous primary colon adenocarcinomas), one had a lymphoma and another one presented a breast cancer. The three patients with CD enteritis developed carcinoid of the appendix (one), sigmoid adenocarcinoma (one) and one lymphoma. Data regarding tumor location and intestinal inflammation is presented in Figure 1.

TABLE 2. Descriptive data on genders for patients with UC and UC associated to neoplasia (colorectal cancer, lymphoma and other tumors)

\begin{tabular}{|c|c|c|c|c|c|}
\hline Sex & $\begin{array}{c}\text { UC } \\
(\mathrm{n}=803)\end{array}$ & $\begin{array}{c}\mathrm{UC}+\mathrm{NEO} \\
(\mathrm{n}=30)\end{array}$ & $\mathrm{UC}+\mathrm{CRC}$ & $\mathrm{UC}+\mathrm{LY}$ & $\mathrm{UC}+\mathrm{OT}$ \\
\hline Female & $\begin{array}{c}460 \\
(59.5 \%)\end{array}$ & $\begin{array}{c}13 \\
(43.3 \%)\end{array}$ & $\begin{array}{c}5 \\
(16.6 \%)\end{array}$ & 0 & $\begin{array}{c}8 \\
(26.7 \%)\end{array}$ \\
\hline Male & $\begin{array}{c}313 \\
(40.5 \%) \\
\end{array}$ & $\begin{array}{c}17 \\
(56.7 \%) \\
\end{array}$ & $\begin{array}{c}8 \\
(26.7 \%) \\
\end{array}$ & $\begin{array}{c}1 \\
(3.3 \%) \\
\end{array}$ & $\begin{array}{c}8 \\
(26.7 \%) \\
\end{array}$ \\
\hline
\end{tabular}

$\mathrm{UC}=$ ulcerative colitis; $\mathrm{NEO}=$ neoplasia $\mathrm{CRC}=$ colorectal cancer LY = lymphoma; OT $=$ other tumors

TABLE 3. Incidence of colorectal and extraintestinal neoplasia among patients with CD and UC

\begin{tabular}{lccc}
\hline Neoplasia & $\begin{array}{c}\text { Crohn's disease } \\
(\mathbf{n}=804)\end{array}$ & $\begin{array}{c}\text { Ulcerative colitis } \\
(\mathbf{n}=803)\end{array}$ & $\begin{array}{c}\text { Statistical } \\
\text { analysis }\end{array}$ \\
\hline Colorectal cancer & $4(0.5 \%)$ & $13(1.7 \%)$ & $\begin{array}{c}\text { Fisher } \\
P=0.2953\end{array}$ \\
Extraintestinal & $4(0.5 \%)$ & $17(2.1 \%)$ & $\begin{array}{c}\text { Chi-square } \\
P=0.0009\end{array}$ \\
Total & $8(0.99 \%)$ & $30(3.7 \%)$ & $P=0.0003$ \\
\hline
\end{tabular}

$\mathrm{CD}=$ Crohn's disease $; \mathrm{UC}=$ ulcerative colitis

\begin{tabular}{|llll|}
\hline Age & Sex & Crohn's disease & Neoplasms \\
\hline 65 & male & colon & colon \\
27 & female & small bowell & appendix carcinoid \\
13 & male & colon & colon \\
20 & female & colon + perianal & breast \\
10 & female & colon + perianal & rectum \\
49 & female & small bowell & colon \\
38 & male & small bowell & cecum lymphoma \\
20 & male & colon & lymphoma \\
\hline
\end{tabular}

FIGURE 1. Clinical data regarding topography of Crohn's disease and site of neoplásica 
The patient with appendix carcinoid was diagnosed simultaneously with CD just 1 year after the onset of symptoms of IBD. The diagnosis was established incidentally during surgery. With the exception of the patient with five tumors, the remaining adenocarcinomas were localized in the distal colon and rectum.

The interval between onset of symptoms and CRC diagnosis varied from less than 1 year in two patients to more than 11 and 14 years for the others, respectively. The patient diagnosed with CRC after 11 years had initially refused to undergo exams due to pain, so the diagnosis was only established during laparotomy to treat intestinal obstruction with a simple colostomy for advanced disease. Regarding the lymphomas, one of them was diagnosed simultaneously and the other case developed 2 years after the onset of $C D$ symptoms. The breast cancer patient developed it 10 years after CD had manifested.

The average age of symptoms onset in CD patients without neoplasia was 29.5 years, and 30.3 years in the group with neoplasia. When the neoplasia was diagnosed, patient's mean age was 35.2 years. The average interval between onset of symptoms and CD diagnosis was 3.0 years (without neoplasia) and 1.6 years (with neoplasia). Follow-up periods of these groups were 10.5 and 6.7 years, respectively.

Four $(0.5 \%)$ patients had sclerosing cholangitis and one of them developed lymphoma. Smoking was referred by $150(18.8 \%)$ patients among 796 without neoplasia and by $4(50 \%)$ out of 8 with neoplasia $(P=0.04)$, suggesting that smoking affects the risk of neoplasia in $\mathrm{CD}(\mathrm{RR}=2.65$; $1.31<\mathrm{RR}, 5.39$ ).

Furthermore, among the group without neoplasia, 128 $(16.1 \%)$ patients reported other types of neoplasia within their families. The same information was discovered in two $(25 \%)$ out of eight patients that developed neoplasia. None of families fulfilled criteria to be categorized as having any form of hereditary CRC syndrome.

In the $\mathrm{CD}$ with $\mathrm{CRC}$ group, one patient died in the same year that the diagnosis was made and another one was lost to follow-up. The remaining two patients are alive 3 and 7 years respectively after diagnosis, both with no evidence of metastasis.

Clinical features from $\mathrm{CD}$ and $\mathrm{UC}$ patients are presented in Table 4.

TABLE 4. Clinical features of Crohn's disease and ulcerative colitis patients

\begin{tabular}{|c|c|c|}
\hline Features & Crohn's disease & Ulcerative colitis \\
\hline Symptoms onset & 30 years & 34 years \\
\hline Smoking habitus & $\begin{array}{l}\text { 150/796 }(18.8 \%) \\
\text { without neoplasia } \\
04 / 08(50 \%) \text { with } \\
\text { neoplasia }\end{array}$ & $\begin{array}{l}98 / 773(12.6 \%) \\
\text { without neoplasia } \\
\text { 02/30 }(6.7 \%) \text { with } \\
\text { neoplasia }\end{array}$ \\
\hline Family history & $\begin{array}{l}\text { 128/796 (16.1\%) } \\
\text { without neoplasia } \\
\text { 02/08 }(25 \%) \text { with } \\
\text { neoplasia }\end{array}$ & $\begin{array}{l}111 / 773(14.4 \%) \\
\text { without neoplasia } \\
02 / 30(6.7 \%) \text { with } \\
\text { neoplasia }\end{array}$ \\
\hline $\begin{array}{l}\text { Mortality from } \\
\text { neoplasia }\end{array}$ & $1 / 8(12.5 \%)$ & $9 / 30(30 \%)$ \\
\hline
\end{tabular}

\section{Patients with UC}

Within this group, 30 (3.7\%) patients developed neoplasia, and the majority of tumors $(63.3 \%)$ occurred in those with extensive colitis (Table 5). Even more, 11 out of 13 patients $(84.6 \%)$ presented left colon tumors. Interestingly, one patient developed a rectal tumor 11 years after an ileorectal anastomosis due to a synchronous right and left colon carcinoma.

TABLE 5. Extent of UC in patients with and without neoplasia (colorectal cancer, lymphoma and other tumors)

\begin{tabular}{lccccc}
\hline UC Extent & UC & UC+NEO & UC+CRC & UC+LY & UC+OT \\
\hline extensive & 295 & 19 & 10 & 0 & $9(30 \%)$ \\
& $(38.2 \%)$ & $(63.3 \%)$ & $(33.3 \%)$ & & \\
left sided & 195 & 3 & 1 & 0 & 2 \\
distal & $(25.2 \%)$ & $(10 \%)$ & $(3.3 \%)$ & & $(6.7 \%)$ \\
& 283 & 8 & 2 & 2 & 4 \\
& $(36.6 \%)$ & $(26.7 \%)$ & $(6.7 \%)$ & $(6.7 \%)$ & $(13.3 \%)$ \\
\hline
\end{tabular}

$\mathrm{UC}=$ ulcerative colitis; $\mathrm{NEO}=$ neoplásica; $\mathrm{CRC}=$ colorectal cancer; $\mathrm{LY}=$ lymphoma; $\mathrm{OT}=$ other tumors

The average age at onset of symptoms was 34.1 years. Length of simptomatology was 11.4 years $(0-26$ years $)$ to CRC diagnosis and 3.5 years to the diagnosis of other neoplasia (excluding the two cases of lymphoma). These lymphoma patients were diagnosed 15 years before the UC and 3 years later, respectively.

The 15 cases of extraintestinal tumors were represented by 6 breast cancers (one of them diagnosed 4 years before the UC symptoms), 2 cholangiocarcinomas and 1 of following locations: brain, lung, prostate, kidney, thyroid, a melanoma and an eye.

Sclerosing cholangitis was present in $14 / 803(1.7 \%)$ patients and $3(21.4 \%)$ of them developed neoplasia (1 cholangiocarcinoma, 1 colonic and 1 rectal adenocarcinoma). The association was statistically significant (Fisher $P=0.01$ ). Smoking habit was reported by $98(12.6 \%)$ out of 773 patients without neoplasia against $2(6.7 \%)$ out of 30 with neoplasia. A positive history of neoplasia within the family was reported by $111 / 773 \mathrm{UC}(14.4 \%)$ patients without neoplasia and by 2 $(6.7 \%)$ out of 30 with neoplasia (Fisher test $P=0.2$ ).

\section{Follow-up and mortality}

Follow-up varied from 1-22 years for both IBD, with medium periods of 10.5 years and 9.6 years for $C D$ and UC patients, respectively. During this period, $13(1.6 \%)$ patients with CD died, but only $1(12.5 \%)$ among the 8 because of a rectal cancer. Among the UC patients, another $13(1.6 \%)$ died, and the mortality related to neoplasia occurred in $9 / 30(30 \%)$.

From the total group, $10(0.6 \%)$ out of 1607 died due to intestinal or extraintestinal neoplasia. Among the 26 deaths, $7(26.9 \%)$ were due to colorectal cancer. The patient with CD and rectal cancer died at 21 years. The six UC patients with CRC died at an average age of 41.4 years and the three UC patients with extraintestinal neoplasia died at an average of 48.7 years. The other patients died from IBD complications (2), from surgical complications (13) and from causes not related to IBD (1). 


\section{DISCUSSION}

As in other countries, the frequency of IBD is increasing in Brazil, especially for DC. For this reason, we decided to evaluate the incidence of intestinal and extraintestinal neoplasia within our series of patients from one single institution, which is the biggest public hospital in South America. Data retrieved from 1607 patients treated between 1984 and 2007 showed prevalence among women $(55.2 \%$ in $\mathrm{CD}$ and $59.2 \%$ for UC), although the incidence of neoplasia was not different among genders. One interesting feature is that patients developed neoplasia earlier than the expected average age for the general population (mean age was 35.2 years for $C D$ ).

The diagnosis of $C D$ was made earlier (1.6 vs 3.0 years) in the group that developed cancer probably because their disease was more severe, fact that could lead them to look sooner for medical attention. On the other hand, the average interval between the onset of CD symptoms and the diagnosis of CRC was small. This fact may be explained by an eventual lack of relation between CD and CRC in these patients. Moreover, CD could be present for a longer time without expressing symptoms, making it difficult to establish the disease's start. Another explanation is that, in these patients, the same genetic alterations that induced CD could enhance the risk of $\mathrm{CRC}$, as the association between familial IBD and genes encoding susceptibility for CRC have been suggested previously ${ }^{(33,35)}$.

As stated before, CD patients may eventually be asymptomatic, while in UC there is a correlation between macroscopic colorectal lesions and symptoms. Due to that, interval between onset of symptoms of UC and diagnosis of CRC is much larger than that presented by DC patients.

Although controversial, cancer risk may vary according to many factors such as sex, disease location, degeneration in inflamed areas, age at onset of CD and disease behavior ${ }^{(23)}$. The finding that CRC was more frequently found in the distal colorectum and diseased areas among our patients is supported by meta-analysis showing that the CRC risk was higher in Crohn's colitis than in ileitis ${ }^{(7)}$. In another study, the relative risk of $\mathrm{CRC}$ in patients with $\mathrm{CD}$ affecting only the small bowel was similar to the general population, while the relative risk increased to 4.6 and 13.3 in patients with ileocolic and colonic disease $\mathrm{e}^{(40)}$.

We also found that the CRC incidence was similar in CD $(0.5 \%)$ and UC $(1.7 \%)$ patients. Similarly, Gillen et al. ${ }^{(15)}$ reported an increased risk (18-19 fold increase) in patients with extensive unresected Crohn's colitis and UC, with an absolute cumulative frequency of $7 \%$ and $8 \%$ after 20 years of symptoms for UC and CD, respectively. In our study, it is not possible to evaluate an eventual influence of biological therapy upon CRC risk as patients in the present series did not receive anti-TNF agents.

There is evidence suggesting that colonoscopic surveillance for long standing disease may reduce CRC risk and its associated mortality ${ }^{(21,39)}$. Otherwise, one should notice that at least 13 of our patients developed neoplasia in less than 2 years from the onset of IBD symptoms, and other 2 patients presented it even before IBD had manifested clinically. This suggests that inflammation may not always be responsible for the malignization process in these cases and in others with extraintestinal neoplasia.

In the present study, patients who had been operated for IBD were not dropped from the cancer risk annalysis for many reasons. Regarding Crohn's disease, even operated patients still present the risk to develop neoplasia in another location (either colon, small bowel and others). And although it is obvious that UC who had undergone total rectocolectomy will not develop colorectal cancer in the future, there have been reported cases of cancer appearing within the ileal pouch or at the anal transitional zone ${ }^{(17)}$. Furthermore, we evaluated the incidence of both intestinal and extraintestinal neoplasia, and the latter is not associated with cancer developing at the colon or at the small bowel during follow-up.

After a median follow-up of 9.6 years, the incidence of CRC among our UC patients (13 out of $803=1.6 \%$ ) was similar to that found by others ${ }^{(10)}$. In a meta-analysis of 194 studies, Eaden et al..$^{(10)}$ found that the cancer cumulative probability for all patients with UC was $2 \%$ at 10 years, $8 \%$ at 20 and $18 \%$ at 30 years, regardless of disease extent; the overall prevalence of CRC in any patient was 3.7\%.

During the last 30 years, IBD treatment has changed a lot. Before 1980, UC used to be clinically treated as long as possible and surgical resection was almost always lead to a terminal and definitive ileostomy. This decision was frequently postponed due to the inherent risks associated with a major abdominal surgery and its long-term morbidity affecting quality of life. But the introduction of restorative ileal pouch-anal anastomosis changed the perspectives of surgical indication among UC patients. Thus, patients refractory to medical treatment and with extensive colitis were operated on sooner. Consequently, this population should not develop $\mathrm{CRC}$ in the future. In this context, it is easy to attest that the available management options may also influence the CRC risk in this population.

Meanwhile, the initial enthusiasm with restorative proctocolectomy decreased overtime due to incidence of pouchitis and other complications during long-term follow-up ${ }^{(38)}$. Once again, a turnover towards medical treatment increased the use of immunosuppressants and biologic therapy in the last years. Theorically, this decrease in surgical treatment may be eventually responsible for a future increase in the neoplasia incidence during the next 10 years. On the other hand, the use of salicylates has been associated with reduced risk of colonic cancer ${ }^{(5)}$.

Askling et al. ${ }^{(1)}$ demonstrated that IBD patients with a family history of colon cancer have a higher risk of CRC, and nearly $10 \%$ of all cases occurred in patients with affected relatives. However, this correlation was not significant among our IBD patients. Even though, we do believe that they deserve a close observation follow-up to verify if they will develop a CRC in the future.

Sclerosing cholangitis is associated with a higher number of hepatic and extra hepatic neoplasias ${ }^{(3,26,22)}$, and it has been suggested that these patients should undergo surveillance 
colonoscopy every year regardless of disease's duration ${ }^{(37)}$. In our series, the numbers are too small to draw any conclusion. The same difficulty occurred to Bernstein et al. ${ }^{(4)}$, who reported this diagnosis in only $5(6.4 \%)$ among 78 IBD patients.

The findings in our series do not support the association of IBD and lymphoma. One patient developed lymphoma 15 years before the onset of IBD symptoms, one simultaneously and two others were diagnosed 2 and 3 years later. Two of the largest population-based studies did not show significantly elevated risk ${ }^{(2,27)}$. In a retrospective study, Bernstein et al. ${ }^{(4)}$ demonstrated an increased risk of lymphoma only in male patients with $\mathrm{CD}$ and it was not related to immunotherapy. The fact that our four patients were all males is in accordance with their results.

There exists a theoretical fear that the prolonged use of azathioprine or its derivatives could induce cancer or lymphoma. In this context, Fraser et al. ${ }^{(12)}$ observed patients receiving azathioprine for 27 months, and after a follow-up of 6.9 years they concluded that the cancer incidence was similar to the observed in patients who did not received the drug. Loftus et al. ${ }^{(28)}$ also demonstrated that the absolute risk of lymphoma remains quite small $(0.01 \%$ per person-year $)$. None of our lymphoma patients received immunosuppressive drugs or biologic therapy.

Although the same suspicious idea has been raised with the use of biological therapy, it is difficult to evaluate this issue as the frequency of lymphoma is very low. It is possible that the increased severity or activity of IBD in referral-based studies may increase this risk regardless of the treatment option $^{(19)}$. Anyway, an increased number of lymphomas were reported by Brown et al. ${ }^{(6)}$ in patients with rheumatoid arthritis. But so far it is impossible to assign a causative effect to the infliximab therapy, mainly because the potential confounding effects of IBD are difficult to separate and they may be synergistic ${ }^{(19)}$.

The association of carcinoid tumors with IBD is rare and controversial $^{(25)}$. There have been reports of carcinoid tumors in areas without inflammation in CD patients, leading the authors to suggest that the development of carcinoid tumors may be secondary to distant proinflammatory mediators ${ }^{(42)}$. In an interesting review, Freeman ${ }^{(14)}$ found 3 cases of appendiceal carcinomas in $441 \mathrm{CD}$ patients who underwent surgery, all of them in female patients. Others believe that there appears to be no evidence to substantiate a direct association between IBD and carcinoid tumor, since the frequency was similar to patients without $\mathrm{IBD}^{(17)}$.

Some data regarding life expectancy in IBD were provided by Jess et al. ${ }^{(18)}$, who observed 6,569 individuals/year during an average interval of 17 years. They noticed 84 deaths among 374 patients for an expected number of 67 , and reported that mortality was more important among women, mainly after 21 years of diagnosis. Twenty-two deaths were related to IBD and seven to gastrointestinal cancer in a nationwide population-based study in Denmark ${ }^{(24)}$. The impact of CD on CRC prognosis revealed that 100 patients with CRC-associated-CD had a poorer prognosis than 71,438 CRC patients without $\mathrm{CD}$. The effect of $\mathrm{CD}$ on $\mathrm{CRC}$ survival was more pronounced during the 1st year after cancer diagnosis, in younger patients, in men, and in patients whose tumors had regional spread.

Poor survival in patients with $\mathrm{CD}$ and gastrointestinal cancer might be explained by delayed diagnosis, as CD symptoms may mask those of the neoplasia ${ }^{(24)}$. This is probably what happened with the patient that died in the present study. As the patient had extensive and painful disease, she refused to undergo examination. Despite been adequately treated for IBD, her disease worsened and the diagnosis of an advanced cancer was established. Thus, an unfavorable outcome under treatment should alert the physician for the need to rule out cancer.

Our mortality due to IBD and gastrointestinal cancer was higher when compared with other studies, as we detected $12.5 \%$ and $30 \%$ mortality rates among CD and UC patients with associated neoplasia, respectively. Among the 26 deaths, $7(26.9 \%)$ were due to CRC. In other series, Persson et al. ${ }^{(32)}$ observed $15(5.9 \%)$ deaths out of 255 due to CRC. Similarly, Ekbom et al. ${ }^{(11)}$ found mortality due to CRC in 14\% (6/43) and due to extraintestinal cancer in 7\% (3/43) among IBD patients. On the other hand, others have found similar survival rates for IBD associated-CRC or sporadic $\mathrm{CRC}^{(9)}$.

Thus, if we consider the high mortality due to neoplasia, it is important to establish a surveillance program for IBD. In this population, screening in younger ages is necessary since they develop neoplasia earlier than the general population. With this regard, colonoscopy has been shown to decrease mortality in both UC and Crohn's colitis ${ }^{(21,36)}$. In the near future, the potential use of chemopreventive agents and biomarkers of malignancy in IBD patients may improve the effectiveness of cancer detection during long-term follow-up.

At this point, it is important to state that our study has some biases. First of all, our hospital is an important tertiary center in Brazil for IBD, so patients with more severe and complicated disease are usually sent to this hospital. Thus, this group of patients may overestimate the cancer risk. Furthermore, it is well recognized that medical treatment of IBD has changed during the last two decades, where the use of immunosuppressants and biologic therapy is recent. As there is a suggestion that aminosalicylates may protect IBD patients from cancer ${ }^{(34)}$, our patients have not been exposed to the same drugs for the same length of time, and this condition is probably associated with distinct individual risks for cancer.

Additionally, different operative techniques may influence the probability of developing cancer, and surgically treated patients may underestimate the true risk of malignancy. At the same time, improvements in early diagnosis and oncological treatment overtime may eventually influence survival comparative studies in long periods of time as they do not reflect the natural evolution of the disease.

Concerning the risk of extraintestinal neoplasia in our study, it was greater among UC ( $2.1 \%$ vs $0.5 \%, P=0.0009)$. Among the reports focusing this specific issue, Bernstein et al..$^{(9)}$ observed an increased rate only for liver and biliary tract malignancies in $\mathrm{CD}$ and $\mathrm{UC}$ patients. They found that 
incidence rates of breast, prostate and respiratory carcinomas were not significantly different compared with the general population.

In a very interesting meta-analysis of 34 studies from the literature ${ }^{(40)}$, the authors evaluated the risk of neoplasia in 60,122 patients with $\mathrm{CD}$ and compared the relative risks of small bowel (RR 28.4), colorectal (RR 2.4), extraintestinal cancers (RR 1.27) and lymphoma (RR 1.42) with the baseline population. They also recommended that patients with extensive colonic disease presenting from a young age should undergo endoscopic surveillance. Moreover, their study found that small bowel and CRC risks were higher in North America and United Kingdom than Scandinavian countries. Similarly, Fornaro et al. ${ }^{(13)}$ also identified a greater risk of gastrointestinal, extraintestinal and hemopoietic cancers in 35 literature publications, reinforcing the importance of identifying groups of CD patients with exposition to risk factors in order to establish correct diagnostic and therapeutic methods.

The role of environmental factors such as smoking in IBD pathogenesis has deserved some attention recently. When compared to non-smokers, this habit has been associated with some deleterious effects such as a worse clinical course, higher therapeutic requirements and disease-related complications, mainly in patients with ileal disease ${ }^{(30)}$. Tobacco consumption may even influence surgical recurrence and disease progression towards fistulizing or stricturing forms. However, the underlying mechanisms are certainly complex and are still subject to research. In this sense, smoking may alter gene expression and inflammatory profiles at the colonic mucosa and other organs ${ }^{(20)}$.

Within a disease that may exhibit different extraintestinal manifestations and may involve distinct parts of the upper gastrointestinal tract, smoking habits may also influence the risk of extraintestinal cancer. In a systematic literature review (1966-2009), Pedersen et al. ${ }^{(31)}$ evaluated 17,052 IBD patients from eight population-based cohort studies. They verified that, although the standardized incidence ratios (SIRs) of EIC were not increased, the risk of individual cancer types differed from that of the background population as well as between CD and UC patients. Site-specific analyses displayed that $\mathrm{CD}$ patients presented an increased risk of cancer of the upper gastrointestinal tract (SIR 2.87, 95\% CI 1.664.96), lung (SIR 1.82, 95\% CI 1.18-2.81), urinary bladder (SIR 2.03, 95\% CI 1.14-3.63), and skin (SIR 2.35, 95\% CI 1.43-3.86). Patients with UC had a significantly increased risk of liver-biliary cancer (SIR 2.58, 95\% CI 1.58-4.22) and leukemia (SIR 2.00, 95\% CI 1.31-3.06) but a decreased risk of pulmonary cancer (SIR $0.39,95 \%$ CI $0.20-0.74$ ).

\section{CONCLUSIONS}

CRC incidence was low and similar in both inflammatory bowel diseases. There was a higher incidence of extraintestinal neoplasia in UC when compared to CD. Neoplasias in IBD developed at a younger age than expected for the general population. Mortality associated with malignancy is significant, affecting $1 / 4$ of the patients with neoplasia.

\section{ACKNOWLEDGMENTS}

The authors would like to thank Flávia Komatsuzaki for the statistical analysis and Dr. César de Almeida Neto for the text review.

Campos FG, Teixeira MG, Scanavini A, Almeida MG, Nahas SC, Cecconello I. Neoplasias intestinais e extraintestinais em pacientes com doença inflamatória intestinal em hospital terciário. Arq Gastroenterol. 2013;50(2):123-29.

RESUMO - Contexto - O desenvolvimento de neoplasias se constitui em preocupação constante em pacientes com doenças inflamatórias intestinais (DII), especialmente o câncer colorretal (CCR). Objetivos - Determinar a incidência de neoplasias intestinais e extra-intestinais entre pacientes com DII. Métodos - Foram obtidas informações de 1607 pacientes, quanto a dados demográficos, duração e extensão da doença, relação temporal entre diagnóstico das DII e neoplasia, evolução clínica e fatores de risco para neoplasia. Resultados - Doença de Crohn (DC) foi mais frequente entre as mulheres $(P=0.0018)$. A incidência de neoplasia foi maior nos doentes com retocolite ulcerativa $(\mathrm{RCU})$ em relação aos com DC $(P=0.0003)$. Oito $(0.99 \%)$ pacientes desenvolveram neoplasia entre 804 com DC: quatro tumores colorretais, dois linfomas, um carcinóide de apêndice e um câncer de mama. Trinta (3.7\%) pacientes desenvolveram neoplasia entre os 803 RCU: 13 CCR, 2 linfomas e 15 tumores extra-intestinais. Enquanto a incidência de CCR não diferiu entre RCU e DC ( $1.7 \%$ vs $0.5 \% ; P=0.2953)$, a incidência de neoplasias extraintestinais foi maior na RCU $(2.1 \%$ vs $0.5 \%, P$ = 0.0009). Dez (26.3\%) pacientes de um total de 38 com neoplasia, evoluíram a óbito durante o seguimento. Conclusões - A incidência de CCR foi baixa e similar em ambas as doenças inflamatórias. Observou-se incidência maior de neoplasia extra-intestinal na RCU quando comparada à DC. Neoplasias em doenças inflamatórias se desenvolveram em idade mais precoce do que a esperada para a população geral. A mortalidade associada a neoplasias é significativa, afetando $1 / 4$ dos pacientes.

DESCRITORES - Neoplasias intestinais. Neoplasias colorretais. Doenças inflamatórias intestinais. Colite ulcerativa. Doença de Crohn. 


\section{REFERENCES}

1. Askling J, Dickman PW, Karlen P, Broström O, Lapidus A, Löfberg R, Ekbom A. Family history as a risk factor for colorectal cancer in inflammatory bowel disease. Gastroenterology. 2001;120:1356-62

2. Askling J, Brandt L, Lapidus A, Karlén P, Björkholm M, Löfberg R, Ekbom A. Risk of hematopoietic cancer in patients with inflammatory bowel disease. Gut. 2005;54:617-22.

3. Bergquist A, Ekbom A, Olsson R, Kornfeldt D, Lööf L, Danielsson A, Hultcrantz R, Lindgren S, Prytz H, Sandberg-Gertzén H, Almer S, Granath F, Broomé U. Hepatic and extrahepatic malignancies in primary sclerosing cholangitis. $\mathrm{J}$ Hepatol. 2002;36:321-7.

4. Bernstein CN, Blanchard JF, Kliewer E, Wajda A. Cancer risk in patients with inflammatory bowel disease: a population-based study. Cancer. 2001;91:854-62.

5. Bernstein CN, Eaden J, Steinhart AH, Munkholm P, Gordon PH. Cancer prevention in inflammatory bowel disease and the chemoprophylatic potential of 5-aminosalicylic acid. Inflamm Bowel Dis. 2002;8:356-61.

6. Brown SL, Greene MH, Gershon SK, Edwards ET, Braun MM. Tumor necrosis factor antagonist therapy and lymphoma development: twenty-six cases reported to the Food and Drug Administration. Arthritis Rheum. 2002;46:3151-8.

7. Canavan C, Abrams KR, Mayberry J. Meta-analysis: colorectal and small bowel cancer risk in patients with Crohn's disease. Aliment Pharmacol Ther. 2006;23:1097-104

8. Crohn B, Rosenberg H. The sigmoidoscopic picture of chronic ulcerative colitis (non-specific). Am J Med Sci. 1925;170:220-8.

9. Delaunoit T, Limburg PJ, Goldberg RM, Lymp JF, Loftus EV Jr. Colorectal cancer prognosis among patients with inflammatory bowel disease. Clin Gastroenterol Hepatol. 2006;4:335-42.

10. Eaden JA, Abrams KR, Mayberry JF. The risk of colorectal cancer in ulcerative colitis: a meta-analysis. Gut. 2001;48:526-35

11. Ekbom A, Helmick CG, Zack M, Holmberg L, Adami HO. Survival and causes of death in patients with inflammatory bowel disease: a population-based study. Gastroenterology. 1992;103:954-60.

12. Fraser AG, Orchard TR, Robinson EM, Jewell DP. Long term risk of malignancy after treatment of inflammatory bowel disease with azathioprine. Aliment Pharmacol Ther. 2003;16:1225-32.

13. Fornaro R, Frascio M, Denegri A, Stabilini C, Impenatore M, Mandolfino F, Lazzara F, Gianetta E. [Chron's disease and cancer]. Ann Ital Chir. 2009;80:119-25.

14. Freeman HJ. Appendiceal carcinoids in Crohn's disease. Can J Gastroenterol. 2003;17:43-6.

15. Gillen CD, Walmsley RS, Prior P, Andrews HA, Allan RN. Ulcerative colitis and CD's disease: a comparison of the colorectal risk in extensive colitis. Gut. 1994;35:1590-2.

16. Greenstein AJ, Sachar DB, Smith H, Janowitz HD, Aufses AH Jr. A comparison of cancer risk in CD's disease and ulcerative colitis. Cancer. 1981;48:2742-5.

17. Greenstein AJ, Balasubramanian S, Harpaz N, Rizwan M, Sachar DB. Carcinoid tumor and inflammatory bowel disease: a study of eleven cases and review of the literature. Am J Gastroenterol. 1997;92:682-5.

18. Jess T, Winther KV, Munkholm P, Langholz E, Binder V. Mortality and causes of death in CD's disease: follow up of a population based cohort in Copenhagen County. Denmark. Gastroenterology. 2002;122:1808-14.

19. Jones JL, Loftus EV Jr. Lymphoma risk in inflammatory bowel disease: is it the disease or its treatment? Inflamm Bowel Dis. 2007;13:1299-307.

20. Joyce MR, Hannaway CD, Strong SA, Fazio VW, Kiran RP. Impact of smoking on disease phenotype and postoperative outcomes for Crohn's disease patients undergoing surgery. Langenbecks Arch Surg. 2013;398:39-45

21. Karlén P, Kornfeld D, Broström O, Löfberg R, Persson PG, Ekbom A. Is colonoscopic surveillance reducing colorectal cancer mortality in ulcerative colitis? A population based case control study. Gut. 1998;42:711-4
22. Kornfeld D, Ekebom A, Ihre T. Is there an excess risk for colorectal cancer in patients with ulcerative colitis and concomitant primary sclerosing cholangitis? A population based study. Gut. 1997;41:522-55.

23. Lakatos PL, David G, Pandur T, Erdelyi Z, Mester G, Balogh M, Szipocs I, Molnar C, Komaromi E, Kiss LS, Lakatos L. Risk of colorectal cancer and small bowel adenocarcinoma in Crohn's disease: a population-based study from western Hungary 1977-2008. J Crohns Colitis. 2011;5:122-8.

24. Larsen M, Mose H, Gislum M, Skriver MV, Jepsen P, Nørgård B, Sørensen HT Survival after colorectal cancer in patients with Crohn's disease: a nationwide population-based Danish follow-up study. Am J Gastroenterol. 2007;102:163-7.

25. Le Marc'hadour F, Bost F, Peoc'h M. Roux JJ, Peoc'h M, Roux JJ, Pasquier D, Pasquier B. Carcinoid tumour complicating inflammatoty bowel disease. A study of two cases with review of the literature. Pathol Res Pract. 1994;190:1185-92;discussion 1193-200.

26. Lewis JD, Deren JJ, Lichtenstein GR. Cancer risk in patients with inflammatory bowel disease. Gastroenterol Clin North Am. 1999;28:459-77.

27. Lewis JD, Bilker WB, Brensiger C, Deren JJ, Vaughn DJ, Strom BL. Inflammatory bowel disease is not associated with an increased risk of lymphoma. Gastroenterology. 2001;121:1080-7.

28. Loftus EV Jr., Tremaine WJ, Habermann TM, Zinsmeister AR, Sandborn WJ. Risk of lymphoma in inflammatory bowel disease. Am J Gastroenterol. 2000;95:2308-12.

29. Morson BC, Pang LS. Rectal biopsy as an aid to cancer control in ulcerative colitis. Gut. 1967;8:423-34

30. Nos P, Domènech E. Management of Crohn's disease in smokers: Is an alternative approach necessary? World J Gastroenterol. 2011;17:3567-74.

31. Pedersen N, Duricova D, Elkjaer M, Gamborg M, Munkholm P, Jess T. Risk of extra-intestinal cancer in inflammatory bowel disease: meta-analysis of population-based cohort studies. Am J Gastroenterol. 2010;105:1480-7.

32. Persson PG, Karlén P, Bernell O, Leijonmarck CE, Broström O, Ahlbom A, Hellers G. CD's disease and cancer: a population-based cohort study. Gastroenterology. 1994; 107:1675-9.

33. Pokorny RM, Hofmeister A, Galandiuk S, Dietz AB, Cohen ND, Neibergs HL. Crohn's disease and ulcerative colitis are associated with the DNA repair gene MLH1. Ann Surg. 1997;225:718-23.

34. Riyaz S, Hamlin J, Everett S. Role of 5-aminosalicylate in preventing colorecta cancer. Am J Gastroenterol. 2011;106:1720-1.

35. Satsangi J, Parkes M, Louis E, Hashimoto L, Kato N, Welsh K, Terwilliger JD, Lathrop GM, Bell JI, Jewell DP. Two stage genome-wide search in inflammatory bowel disease provides evidence for susceptibility loci in chromosomes 3,7 and 12. Nat Genet. 1996;14:199-202.

36. Siegel CA, Sands BE. Risk factors for colorectal cancer in Crohn's colitis: a case control study. Inflamm Bowel Dis. 2006;12:491-6.

37. Soetikno RM, Lin OS, Heidenreich PA, Young HS, Blackstone MO. Increased risk of colorectal neoplasia in patients with primary sclerosing cholangitis and ulcerative colitis: a meta-analysis. Gastrointest Endosc. 2002;56:48-54

38. Teixeira MG, Ponte ACA, Sousa M, Almeida MG, Silva-Filho E, Calache JE, Habr-Gama A, Kiss DR. Short and long term outcome of ileal pouch-anal anastomosis for ulcerative colitis. Rev Hosp Clin Fac Med Sao Paulo. 2003;58:193-8.

39. Velayos FS, Loftus EV Jr, Jess T, Harmsen WS, Bida J, Zinsmeister AR, Tremaine WJ, Sandborn WJ. Predictive and protective factors associated with colorectal cancer in ulcerative colitis: a case control study. Gastroenterology. 2006;130:1941-9.

40. von Roon AC, Reese G, Teare J, Constantinides V, Darzi AW, Tekkis PP. The risk of cancer in patients with CD's disease. Dis Colon Rectum. 2007;50:839-55.

41. Warren S, Sommers SC. Pathogenesis of ulcerative colitis. Am J Pathol 1949;25:657-79.

42. West NE, Wise PE, Herline AJ, Muldoon RL, Chopp WV, Schwartz DA. Carcinoid tumors are 15 times more common in patients with Crohn's disease. Inflamm Bowel Dis. 2007;13:1129-34. 